\title{
Aplikasi Pendeteksi Asap Berbasis Arduino Uno pada Platform Android
}

\author{
Liza Fitriana', Frinanta Ananda²
}

Address: Universitas Harapan Medan/ Fakultas Teknik dan Komputer, Program Studi Manajemen Informatika, Indonesia

Email: lizafitriana@outlook.com

\begin{abstract}
Abstrak
Asap merupakan efek samping dari hasil pembakaran yang tidak sempurna dari suatu bahan bakar. Selain memberikan dampak yang merugikan, asap juga dapat diperlukan untuk hal-hal yang bermanfaat seperti: pembasmian hama, aroma therapy, dan lain-lain. Kehadiran asap dapat suatu ruangan, selain yang disengaja untuk memberikan manfaat, dapat mengindikasikan terjadinya kebakaran. Umumnya jika terjadi kebakaran dalam suatu gedung, korban yang meninggal akibat menghirup asap yang terlalu lama akan lebih banyak dibandingkan dengan korban yang terbakar. Untuk itu diperlukan suatu perangkat yang dapat mendeteksi kehadiran asap tersebut. Dalam hal ini, kami merancang suatu alat yang menggunakan arduino untuk mendeteksi kehadiran asap yang mana hasilnya berupa pemberitahuan, baik pada layar komputer ataupun pada gawai (gadget). Pemberitahuan tersebut berisi tentang keadaan udara pada saat itu, apakah baik, buruk ataupun lainnya, dimana klasifikasinya disesuaikan dengan Indeks Standar Pencemaran Udara (ISPU) yang dikeluarkan oleh Kepala Badan Pengendalian Dampak Lingkungan.
\end{abstract}

Keywords - smoke, sensor, microprocessor, arduino, mobile

\section{Latar Belakang}

Berbicara tentang asap mungkin saja akan tergambar dalam benak kita kumpulan udara yang terkadang terasa panas. Hal ini disebabkan karena asap merupakan sisa pembakaran yang kurang sempurna.

Asap dapat saja memberikan efek yang bermanfaat ataupun merugikan bagi makhluk hidup di sekitarnya. Berdasarkan pertimbangan tersebut, adalah penting bagi manusia untuk mengetahui kondisi ruangan yang disebabkan oleh asap yang berada di sekitarnya. Untuk itu kami merancang pembuatan aplikasi pendeteksi asap berbasis Arduino Uno pada platform android, selain platform komputer.

Arduino Uno merupakan adalah pengembangan mikrokontroller berbasis ATMega328. Arduino merupakan sebuah platform komputasi fisik (Physical Computing) yang open source pada board input ouput sederhana. Maksud dari platform komputasi fisik adalah sebuah sistem fisik yang interaktif dengan penggunaan software dan hardware yang dapat mendeteksi dan merespons situasi dan kondisi.

Arduino Uno memiliki 14 (empat belas) kaki digital untuk input dan output. Sebanyak 6 (enam) dari 14 (empat belas) kaki tersebut dapat digunakan sebagai sinyal PWM (Pulse Width Modulation). Selain itu Arduino juga dilengkapi dengan sebuah koneksi USB, sebuah konektor listrik, sebuah kaki header dari ICSP, dan sebuah tombol reset yang berfungsi untuk mengulang program.

Kelebihan Arduino diantaranya adalah tidak perlu perangkat chip programmer karena didalamnya sudah ada bootloader yang akan menangani upload program dari komputer, Arduino sudah memiliki sarana komunikasi USB, sehingga pengguna laptop yang tidak memiliki port serial/RS323 bisa menggunakannya [1]. Arduino dilengkapi dengan software yang cukup lengkap serta 
memiliki modul siap pakai (shield) yang dapat ditancapkan pada papan (board) nya.

Android merupakan platform open source yang komprehensif serta dirancang untuk mobile devices, dimana semua tools dan frameworks tersedia dengan lengkap di dalamnya. Sistem Android menggunakan basis data (database) SQLite untuk menyimpan informasi penting yang diperlukan. agar tetap tersimpan meskipun device dimatikan.

Banyak riset yang menggunakan Arduino Uno ataupun platform Android untuk membuat alat yang dapat membantu manusia dalam berbagai macam keperluan, antara lain:

1. Membuat alat kontrol pintu pintu gerbang secara elektronik untuk keamanan rumah harus menggunakan kunci konvensional [1].

2. Membuat pengontrol suhu ruangan [3].

3. Membuat sistem kendali suhu dan pemantauan kelembaban udara ruangan [4].

4. Membuat pengendali kecepatan putaran motor DC terhadap perubahan temperatur dengan sistem modulasi lebar pulsa [6].

5. Membangun prototipe sistem pengendalian peralatan listrik [7].

6. Membuat alat peraga yang dapat memperkenalkan dasar - dasar elektronika digital dan teknologinya yang bekerja di komputer atau laptop sebagai media untuk memprogram alat peraga tersebut [11].

7. Membuat Sistem Home Automation untuk memantau tamu yang datang pada monitor melalui kamera CCTV [13].

Berdasarkan uraian di atas, maka tujuan dari pembuatan alat pendeteksi asap ini adalah memberitahukan kepada pengguna aplikasi tentang keadaan udara di sekitarnya berdasarkan asap yang dideteksi oleh sensor yang tersedia.

\section{Metode}

Alat untuk mendeteksi pencemaran udara terdiri dari Sensor Asap (MQ7), Arduino UNO , Android, dan bluetooth. Sensor MQ7 berfungsi untuk menginput perubahan tegangan dari analog ke digital yang akan diteruskan ke mikrokontroler, dalam hal ini Arduino UNO. Untuk menampilkan hasil pendeteksian udara dalam suatu ruangan pada layar komputer ataupun android, maka akan ditanamkan suatu program pada mikrokontroler. Bluetooth digunakan untuk menghu- bungkan antara arduino dengan android dalam menampilkan hasil dari pengukuran.

Proses pendeteksian asap dimulai pada saat sensor MQ7 mendeteksi frekwensi udara yang terdapat dalam suatu ruangan. Lalu hasil perhitungan tersebut dikirim ke Arduino yang akan di konversi sesuai dengan satuan ISPU. Setiap perubahan tegangan sebesar $5 \mathrm{mV}$ akan dikonversi ke perubahan 1 ISPU. Setelah nilai ISPU didapatkan, lalu dilakukan pengklasifikasian untuk menentukan keadaan udara di ruangan tersebut.

Untuk mengetahui besarnya nilai ISPU tersebut, maka dapat dilihat pada monitor komputer ataupun telepon selular / mobile phone yang terhubung dengan Arduino. Semakin besar nilai yang ditunjukkan oleh monitor maka tinggi tingkat pencemaran udara di ruangan tersebut.

Lebih jelasnya tentang sistem yang dirancang dapat dilihat pada gambar 1 dan 2 .

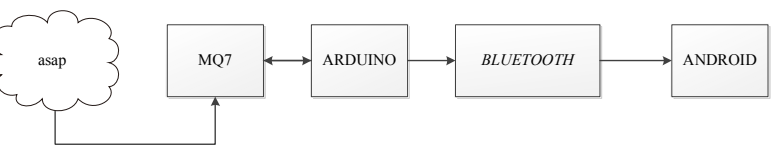

Gambar 1. Skema Sistem pengukur asap dengan menggunakan Bluetooth

Adapun skema pengukuran asap dengan menggunakan USB dapat dilihat pada Gambar 2.

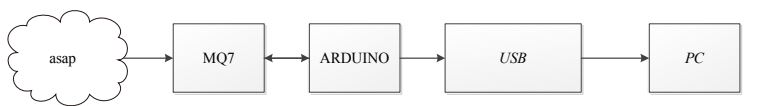

Gambar 2. Skema Sistem pengukur asap dengan menggunakan USB

Adapun alur kerja secara keseluruhan dari system yang dirancang dapat dilihat dalam diagram alir (flowchart) yang terdapat pada Gambar 3. 


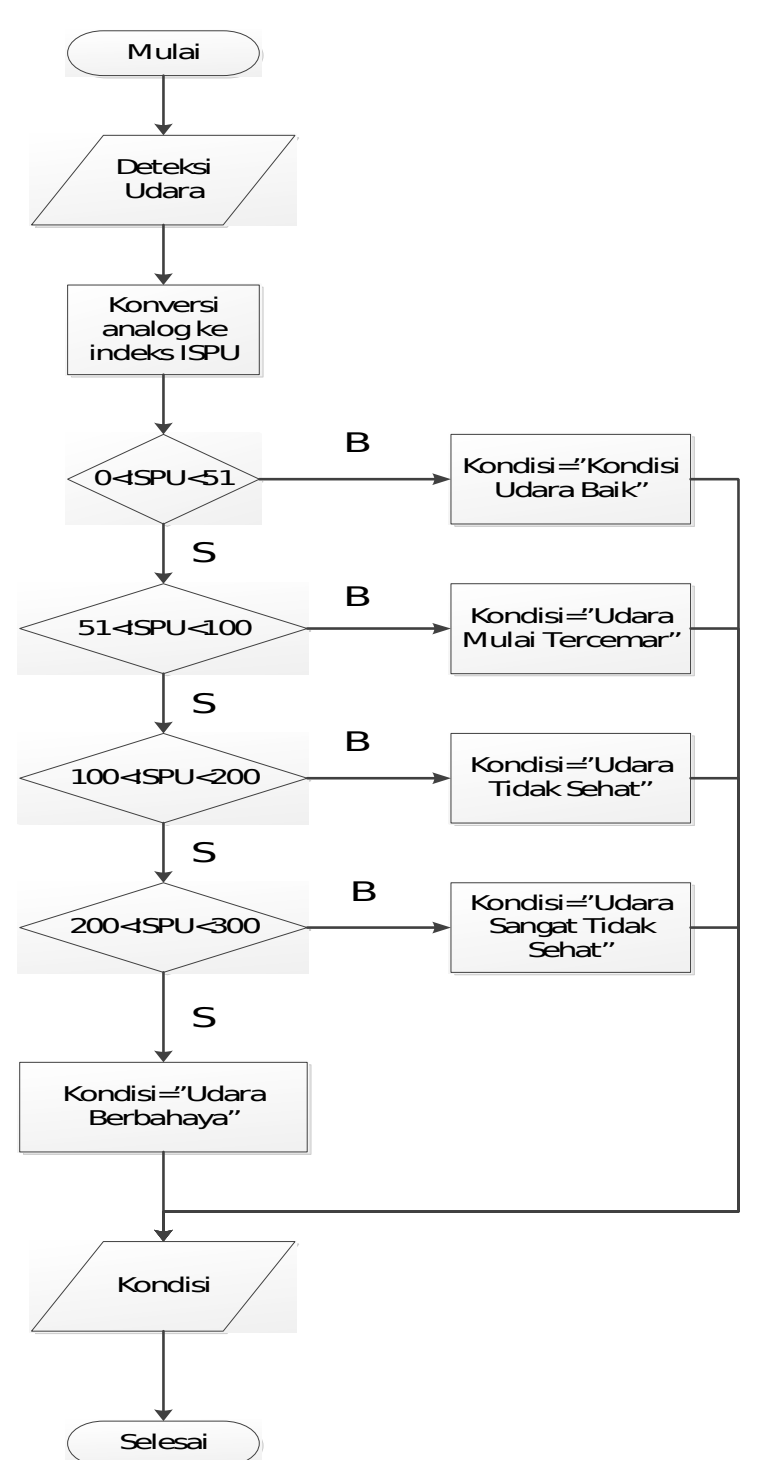

Gambar 3. Diagram alir sistem yang dirancang

Setelah pendeteksian asap dilakukan oleh MQ7, maka arduino akan melakukan proses konversi sesuai dengan standar yang terdapat dalam ISPU. Setelah nilai hasil konversi didapat, maka proses klasifikasi dilakukan sesuai data yang tertera pada Tabel 1.

Tabel 1. Angka dan Kategori Indeks Standar Pencemaran Udara (ISPU)

\begin{tabular}{|c|c|}
\hline Indeks & Kategori \\
\hline $1-50$ & Baik \\
\hline $51-100$ & Sedang \\
\hline $101-$ & Tidak Sehat \\
\hline
\end{tabular}

Program Studi Teknik Informatika

Universitas Prima Indonesia (UNPRI) Medan

\begin{tabular}{||c|c||}
\hline 199 & \\
\hline $\begin{array}{c}200- \\
299\end{array}$ & $\begin{array}{c}\text { Sangat Tidak } \\
\text { Sehat }\end{array}$ \\
\hline $\begin{array}{c}300- \\
\text { lebih }\end{array}$ & Berbahaya \\
\hline
\end{tabular}

\section{Hasil}

Setelah merancang sistem, maka dilakukan peng-ujian terhadap sistem tersebut. Proses pengujan dila-kukan dengan membuat simulasi kebakaran dimana alat pendeteksi asap diletakkan pada jarak-jarak tertentu dari sumber api.

Untuk itu ditentukan jarak yang akan diuji adalah dekat sumber api (dalam miniatur ruangan yang berukuran sekitar 15 (lima belas) centimeter $\times 15$ (lima belas) centimeter. Jarak selanjutnya adalah 1 (satu) meter, dan jarak terakhir adalah 5 (lima) meter.

Ketika udara mulai tercemar, maka sensor akan medeteksi frekwensi yang bersifat nilai analog yang akan dikalkulasikan agar menampilkan pencemaran udara sebenarnya dengan menggunakan rumus yang ada di bawah ini.

dimana:

$$
\mathrm{T}=\operatorname{asap} *(500.0 / 1024.0)
$$

$$
\mathrm{T}=\text { asap }
$$

Dan hasil pengujian yang dilakukan dapat dilihat dalam Tabel 2.

Tabel 2. Hasil pengujian sistem pada perangkat berbasis android

\begin{tabular}{|l|l|c|}
\hline NO & Jarak & ISPU \\
\hline 1 & Miniatur & 294.23 \\
\hline 2 & 1 (satu) $\mathrm{m}$ & 112.41 \\
\hline 3 & 5 (lima) $\mathrm{m}$ & 72.83 \\
\hline
\end{tabular}

Adapun hasil yang ditunjukkan para gawai dapat dilihat pada Gambar 4, 5, dan 6. 


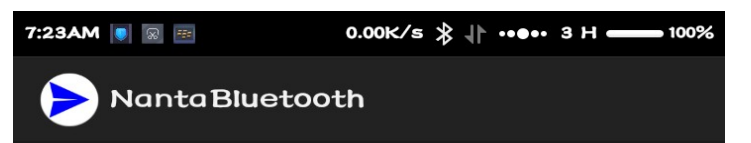

Keterangan ISPU

0-50 normal

51-99 sedang

100-199 tidak sehat

200-299 sangat tidak sehat

$300-500$ berbahaya

\section{Indeks Asap}

294.23

LED HIDUP

LED MATI

Gambar 4. Tampilan sistem yang tertera pada layar gadget pada miniatur

\section{6:27AM 国闻间国国 $0.00 \mathrm{~K} /$ \\ Keterangan ISPU}

0-50 normal

51-99 sedang

100-199 tidak sehat

200-299 sangat tidak sehat

300-500 berbahaya

Indeks Asap

112.41

LED HIDUP

LED MATI

Gambar 5. Tampilan sistem yang tertera pada layar gadget pada jarak $1 \mathrm{~m}$ dari sumber asap

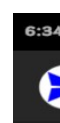

Indeks Asap

72.83

Gambar 6. Tampilan sistem yang tertera pada layar gadget pada jarak $5 \mathrm{~m}$ dari sumber asap 
Aplikasi dan Arduino dihubungkan dengan menggunakan bluetooth. Ketika aplikasi mobile dijalankan dan memilih port Arduino yang terbaca di dalam mobile, akan memilih Baud Rate (satuan kecepatan dalam mengirim data) sebesar 9600, secara langsung berinteraksi dengan aplikasi mobile dan segera merespon untuk mengeluarkan output dari Arduino secara visual.

Untuk aplikasi yang dihubungkan dengan komputer, maka ketika port Arduino telah terbaca oleh komputer lalu dipilih Baud Rate (satuan kecepatan dalam mengirim data) yaitu 9600, secara langsung berinteraksi dengan aplikasi komputer dan segera merespon untuk mengeluarkan output dari Arduino secara visual.

Dengan jarak yang sama, dilakukan simulasi pada sistem yang mana hasilnya ditunjukkan pada Tabel 3.

Tabel 3. Hasil pengujian sistem pada komputer

\begin{tabular}{|l|l|c|}
\hline NO & Jarak & ISPU \\
\hline 1 & Miniatur & 339.20 \\
\hline 2 & 1 (satu) $\mathrm{m}$ & 128.54 \\
\hline 3 & 5 (lima) $\mathrm{m}$ & 65.49 \\
\hline
\end{tabular}

Hasil yang ditampilkan pada layar komputer ditunjukkan pada Gambar 7, 8, dan 9.

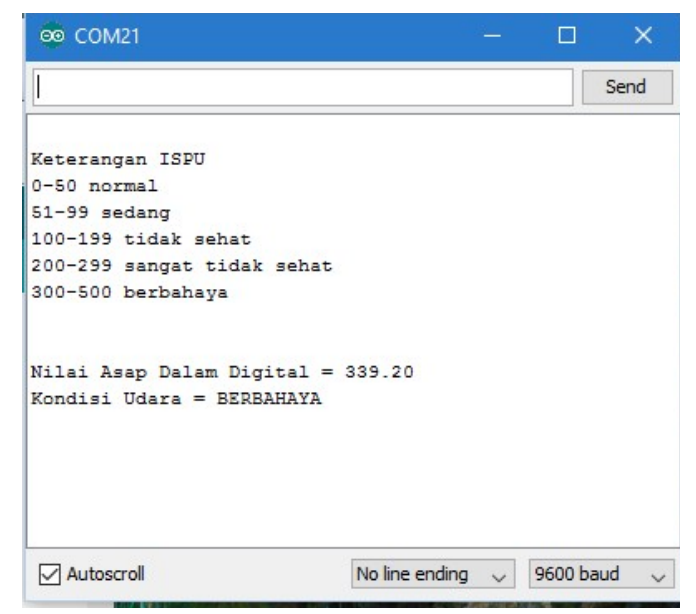

Gambar 7. Tampilan sistem yang tertera pada layar komputer pada miniatur

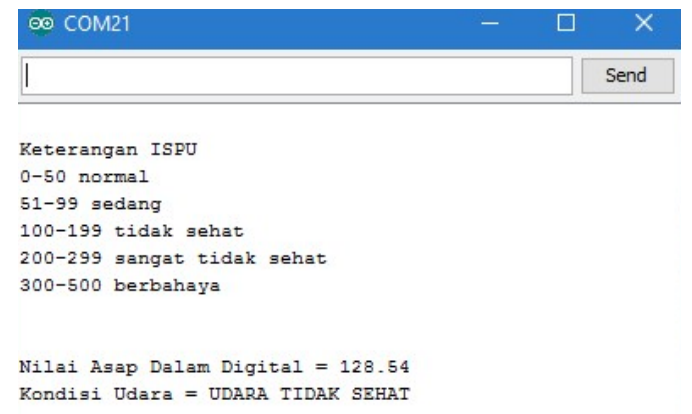

$\square$ Autoscroll No line ending $\checkmark 9600$ baud

Gambar 8. Tampilan sistem yang tertera pada layar komputer pada jarak $1 \mathrm{~m}$ dari sumber asap

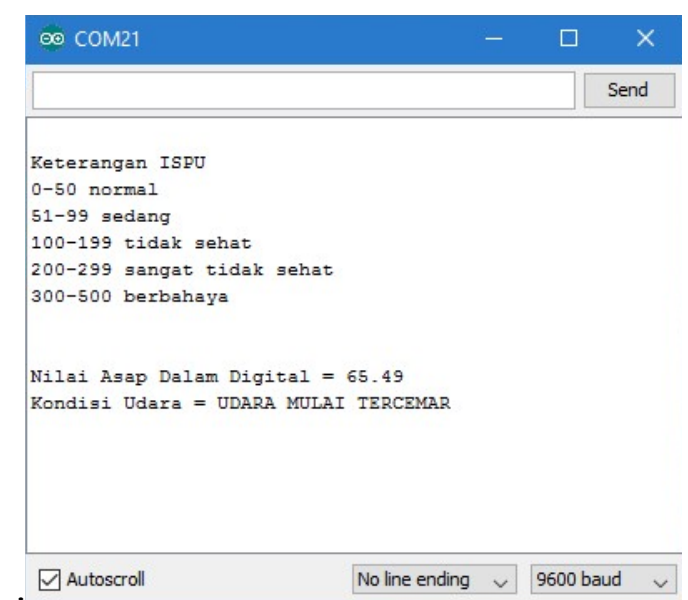

Gambar 9. Tampilan sistem yang tertera pada layar komputer pada jarak $5 \mathrm{~m}$ dari sumber asap

\section{Kesimpulan}

Berdasarkan pengujian terhadap sistem yang telah dibuat, maka diperoleh kesimpulan bahwa aplikasi pendeteksi asap bekerja dengan baik. Semakin jauh jarak antara sensor dengan sumber asap, maka indeks yang diberikan semakin menunjukkan ke arah tingkat pencemaran udara yang lebih rendah.

Untuk lebih mengoptimalkan sensifititas dalam mendeteksi tingkat pencemaran udara, maka perlu diletakkan sensor pada tempat-tempat yang memiliki potensial tinggi dalam hal terjadinya kebakaran.

\section{References}

[1] A.F. Silvia, E. Haritman, Y. Muladi, “Rancang Bangun Akses Kontrol Pintu 
Gerbang Berbasis Arduino Dan Android", Electrans, 2014, Vol. 13 No. 1, Hal. 1-10

[2] C.R. Robertson, Fundamental Electrical and Electronic Principles, Third Edition, Oxford, Newnes, 2008.

[3] Dias Prihatmoko, "Perancangan Dan Implementasi Pengontrol Suhu Ruangan Berbasis Mikrokontroller Arduino Uno", Jurnal SIMETRIS, 2016, Vol. 7, No. 1. Hal. 117-122.

[4] H.I. Islam dkk., (Oktober 2016). Sistem Kendali Suhu Dan Pemantauan Kelembaban Udara Ruangan Berbasis Arduino Uno Dengan Menggunakan Sensor Dht22 Dan Passive Infrared (PIR). Prosiding Seminar Nasional Fisika ( $E$ Jurnal). 5. Hal. 119-125.

[5] M. Banzi, Getting Started with Arduino, First Edition, Sebastop.ol: O'Reilly, 2008.

[6] M. Hamdani, "Pengendali Kecepatan Putaran Motor DC Terhadap Perubahan Temperatur Dengan Sistem Modulasi Lebar Pulsa", Depok, Universitas Indonesia, 2010.

[7] M. Ichwan, M.G. Husada, dan M.I. Ar rasyid, "Pembangunan Prototipe Sistem Pengendalian Peralatan Listrik Pada Platform Android", Jurnal Informatika, 2013, No. 1 Vol. 4, Hal 13-25.

[8] M. Mc Roberts, Ardunio Starter Kit Manual - A Complete Beginner Guide to the Arduino. UK. Earthshine Design, 2009.

[9] Santosa, Pemrograman Delphi Dengan Arduino Uno. Santosa, Jakarta, 2014.

[10] Santosa, Sistem Arduino Uno, Santosa, Jakarta, 2012.

[11] S.J. Sokop, dkk., 2016, Trainer Periferal Antarmuka Berbasis Mikrokontroler Arduino Uno, E-Journal Teknik Elektro Dan Komputer, Vol. 5 No.3. Hal 13-23.

[12] S. Afri, 20 Aplikasi Mikrokontroler ATMega 8535 dan ATMega16, Andi, Yogyakarta, 2011.

[13] T. P. Tambak dan T.A. Bahriun, "Perancangan Sistem Home Automation Berbasis Arduino Uno", Singuda Ensikom, 2015, Vol. 10 No. 28, Hal 121-126. 